\title{
Lessons from the Embryonic Neural Stem Cell Niche for Neural Lineage Differentiation of Pluripotent Stem Cells
}

\author{
Valeriya Solozobova • Nicolas Wyvekens • Jan Pruszak \\ Published online: 25 May 2012 \\ (C) The Author(s) 2012. This article is published with open access at Springerlink.com
}

\begin{abstract}
Pluripotent stem cells offer an abundant and malleable source for the generation of differentiated cells for transplantation as well as for in vitro screens. Patterning and differentiation protocols have been developed to generate neural progeny from human embryonic or induced pluripotent stem cells. However, continued refinement is required to enhance efficiency and to prevent the generation of unwanted cell types. We summarize and interpret insights gained from studies of embryonic neuroepithelium. A multitude of factors including soluble molecules, interactions with the extracellular matrix and neighboring cells cooperate to control neural stem cell self-renewal versus differentiation. Applying these findings and concepts to human stem cell systems in vitro may yield more appropriately patterned cell types for biomedical applications.
\end{abstract}

Keywords Embryonic stem cells $\cdot$ Induced pluripotent stem cells $\cdot$ Neural stem cells $\cdot$ Stem cell niche $\cdot$ Self-renewal

Differentiation · Growth factors · Extracellular matrix ·

Surface molecules

\section{Introduction}

Pluripotent stem cells (PSCs), i.e. embryonic stem (ES) cells and induced pluripotent stem (iPS) cells represent particularly

V. Solozobova $\cdot$ N. Wyvekens $\cdot$ J. Pruszak $(\bowtie)$

Emmy Noether Group for Stem Cell Biology,

Department of Molecular Embryology,

Institute of Anatomy and Cell Biology, University of Freiburg,

Albertstrasse 17,

79104 Freiburg, Germany

e-mail: jan.pruszak@anat.uni-freiburg.de

J. Pruszak

Center for Biological Signaling Studies (BIOSS),

Albertstrasse 19,

79104 Freiburg, Germany attractive cell sources for regenerative medicine [1, 2]. They exhibit vast expansion potential and tissue availability, an ability to be patterned toward the widest range of cellular phenotypes, and provide feasible options for standardization and scale-up of therapeutic cell differentiation $[3,4]$. One challenge, however, remains how to control this vast potential and exploit it so to appropriately guide this cell source from pluripotency exclusively toward the phenotype of biomedical interest. Cellular heterogeneity can be considered an inherent confounding feature of PSC differentiation systems [5, 6]: in contrast to the orchestrated, highly reproducible and precisely timed development occurring during ontogeny of the embryo, a greater variety of developmental stages and cell types exist in these artificial in vitro development systems. In vivo, features of pluripotency are merely present at the earliest stages of development (blastocyst toward epiblast stage) and reliably decline after ca. five days in the mouse (Theiler stage 8) and after 10 to 15 days (Carnegie stage 5) in humans. In contrast, a remaining concern of PSC differentiation systems is the carryover of proliferative stem cells to later stages of in vitro development $[5,7,8]$. In addition to contaminating pluripotent cells, the presence of precursor cells and other cell types that would never co-exist within the same developmental tissue compartment during physiological development in vivo may interfere with cellular patterning efforts in the dish. The key concept of such reasoning is that current in vitro differentiation approaches do not sufficiently take into account the interactions of cells with one another and with the resulting extracellular microenvironments in the dish. This will be of critical importance, however, as full control over proliferation and targeted differentiation of stem cells represents a prerequisite to their safe and efficient use in biomedical applications including cell transplantation and in vitro pharmacological screens.

We aim to exploit insights into physiological neural development to devise better in vitro stem cell differentiation systems for future biomedical approaches aimed at 
alleviating neurological disease. In the embryo, occurring at day seven in the mouse (Theiler stage 11), and ca. week four post-conception in humans (Carnegie stage 9), invaginating neural cells eventually form a tube of columnar neuroepithelial cells. Along this neural tube, a pseudostratified neuroepithelium develops that gives rise to the central nervous system (CNS), i.e. the spinal cord and brain. As the divergent macroscopic dimensions of these latter two structures demonstrate, regulation of self- renewal versus differentiation within this germinal layer must be tightly controlled: the cranial portion of the neural tube generating the rather prolific telencephalic tissue mass and the caudal portion the comparatively limited amount of neurons constituting the gray matter of the spinal cord. Insights into the mechanisms regulating the delicate balance between proliferation versus differentiation in the embryonic neuroepithelial stem cell niche will enable us to much more appropriately modulate in vitro conditions for the generation of specialized neural cell types from PSCs.

Stem cell niches are defined as microenvironments that maintain survival, self-renewal, activation, proliferation and regenerative capacity of stem cells $[9,10]$. Whether in the developing embryo or in vitro, signaling via soluble factors, via the extracellular matrix (ECM) and direct cell-cell interactions via cell surface molecules contribute to controlling appropriate stem cell function. In vivo, most stem cells niches contain basement membranes and vascular elements [11]. In addition to their function as adhesion anchor points, these ensure stem cell integrity and growth control, as well as appropriate cell polarization and orientation. Furthermore, ECM components within stem cell niches are able to trap growth factors, thereby regulating their local concentration and availability.

Neural stem cells (NSCs) are self-renewing, multipotent cells that are present in the embryonic as well as the adult CNS. During early embryogenesis of mammals, the neural plate and neural tube consist of a single layer of proliferating neuroepithelial cells. These primary NSCs have the capacity to self-renew and, neurogenesis preceding gliogenesis, give rise to the neurons of the CNS and radial glia as well as to astrocytes and oligodendrocytes. These NSCs express markers including the intermediate filament nestin, and the transcription factors Pax6 and Sox2. Neuroepithelial cells extend from the ventricular (apical) to the pial (basal) surface (apico-basal polarity), and the migration of nuclei from one to another (interkinetic nuclear migration) creates the impression of a multi-layered (pseudostratified) epithelium [12]. In order to grow in numbers during early embryogenesis, neuroepithelial cells divide symmetrically to produce two identical daughter cells. Later, in the mouse brain after embryonic day (E)11, neuroepithelial cells switch to various modes of asymmetric cell divisions that generate two distinct daughter cells, a self-renewing stem cell and a differentiating neuroblast $[13,14]$.
During the transition to multi-layered neural tissue neuroepithelial cells produce radial glia cells that succeed the early neuroepithelium and exhibit many similar properties but also possess some unique glial characteristics. They express markers such as 3CB2 (a putative intermediate filament-associated protein), radial glial marker-2 (clone RC2), as well as nestin, vimentin and glial fibrillary acidic protein (GFAP), among others. Both neuroepithelial and radial glia cells are capable of self-renewal and generate neurons, intermediate progenitors (basal progenitors) and glia, and both cell types are characterized by apico-basal polarity, exhibit interkinetic nuclear migration and are nestin-positive and prominin-1-positive [13]. Radial glia also provide the substrate for migration of newly formed postmitotic neurons along their radial glial processes [15] which is critical for cortex layer formation in a defined temporal and spatial order.

While proliferation and differentiation of the nervous system of mammals is limited after conclusion of fetal development [16], certain circumscribed areas in the brain retain multipotent cells with the ability to self-renew and to differentiate into neural lineages: the subependymal layer of the subventricular zone (SVZ) of the lateral ventricles and the subgranular zone of the dentate gyrus in the hippocampus $[17,18]$. Both primary fetal tissue- and adult brainderived NSCs can be maintained and propagated in vitro as three-dimensional aggregates, termed neurospheres. Neurosphere formation from primary neural tissue was first explored by Reynolds and Weiss, who demonstrated the presence of expandable NSCs in the mammalian adult brain by isolating them from CNS tissue. These cells were able to generate astrocytes and neurons [19]. This technique continues to be routinely used for expansion and study of adult and embryonic NSCs.

Since the derivation of human ES [1] and more recently iPS cells $[2,20]$, a number of neural induction protocols have been devised and optimized so to reliably and efficiently generate neuroepithelial progeny from pluripotent sources [21-23]. After induction of adherent PSC cultures with neuralizing agents such as Noggin or other bone morphogenetic protein (BMP)/Smad inhibitors [24, 25] characteristic differentiation toward neuronal, astroglial and oligodendroglial sublineages has been established. Combined with their capacity for extended self-renewal and positivity for nestin, Sox 2 and Pax6, this suggests phenotypic features analogous to embryonic NSCs [23] (Fig. 1). Nevertheless, further characterization of PSC-derived NSCs is undoubtedly needed with respect to their precise developmental stage(s) and potency.

We aim to synergize and integrate what is known about the respective roles of growth factors, the ECM, and cellcell interactions for growth and differentiation of developing NSCs. Moreover, we hypothetically discuss potential 
Fig. 1 Neural stem cell proliferation and differentiation in vitro. Phase contrast microphotographs illustrating dense clusters of proliferative neural cells (arrows) which are present in NSC culture from primary cortical tissue (left panel), as well as in NSC cultures derived from human iPS cells (right panel). In both cases, differentiating, processbearing neurons (arrowheads) emerge from the proliferative core. Scale bar: $50 \mu \mathrm{m}$
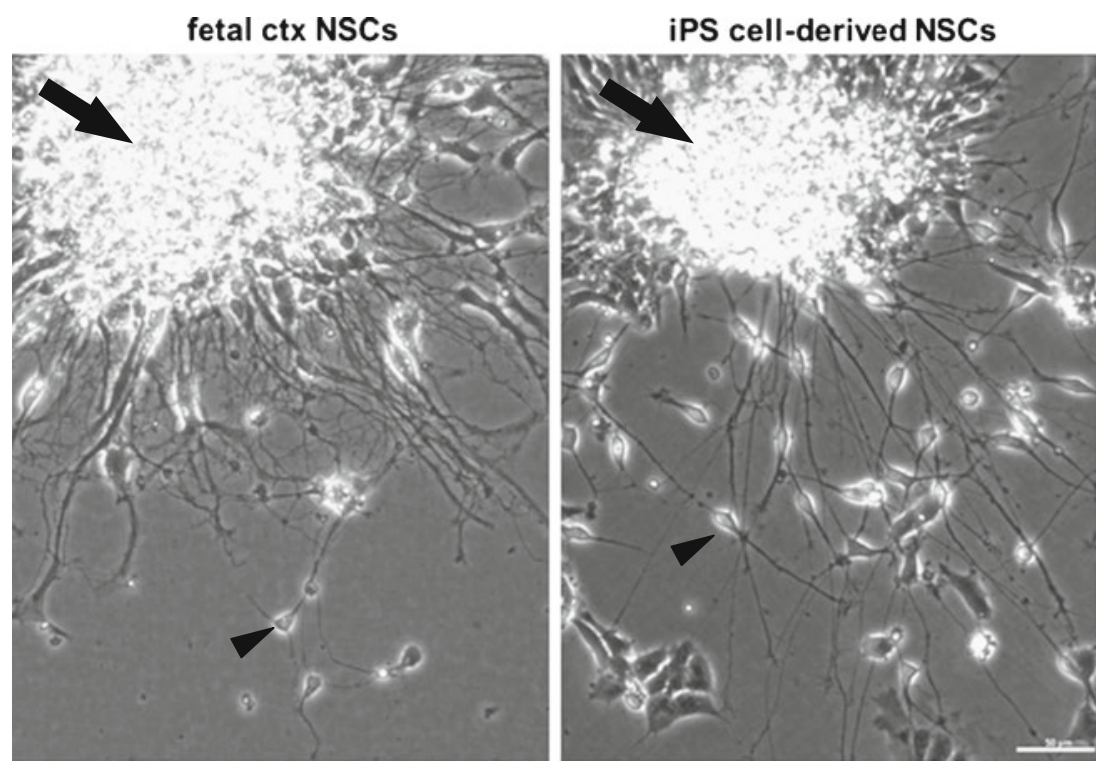

converging downstream pathways of these NSC regulators in order to exploit these insights for improved differentiation of neural cell types from PSCs.

\section{Microenvironmental Factors Controlling the Neural Stem Cell and Neurogenic Niche}

Even free-floating neurosphere cultures arising from a single NSC after multiple cycles of divisions comprise many cells types, including NSC and various differentiated progenitors embedded within these spherical cultures [26, 27]. This underlines the ability of cells in culture to generate their own microenvironment through autocrine, paracrine and exocrine soluble signaling factors (Table 1), through secretion and modulation of ECM components (Table 2), through direct cell interactions with one another via surface molecule-mediated signaling (Table 3), as well as through mechanosensory signals related to tension gradients across the sphere [28-30]. To fully control stem cell development in in vitro differentiation systems we will need to better understand the influence of these processes over an NSC's choice either to reenter the cell cycle and proliferate or to exit and differentiate.

\section{Soluble Factors}

There are several excellent and detailed review articles elucidating the role of growth factors, chemokines and cytokines in NSC development [31-34], and in the following we merely sketch out and exemplify major interdependent growth factor pathways contributing to controlling the neurogenic niche (see Table 1). Early in development, NSCs are mainly responsive to basic fibroblast growth factor (bFGF) signaling, with a later shift to epidermal growth factor (EGF) responsiveness $[35,36]$. EGF receptor numbers increase over time of development, and while BMP signaling inhibits EGFR expression, bFGF can act as an antagonist of BMP4 and promote EGF responsiveness [37]. Empirically, mitogens such as bFGF and EGF have successfully been employed for in vitro expansion of embryonic as well as adult NSCs $[26,38]$. The ECM-modulatory proteinase inhibitor Cystatin-C (CST3) extracted from conditioned medium of NSCs cultures has been shown to cooperate with bFGF to induce NSC proliferation [39]. In addition to extrinsic supplementation of growth factors in culture media, autocrine/paracrine factors including insulin and insulin-like growth factor (IGF) have been suggested to play a role [40, 41]. IGF-1 and -2 receptors are expressed throughout embryological CNS development, and both IGF receptors and ligands are present in the germinal zone and SVZ. In vivo, mouse mutants for IGF as well as IGF receptors display brain developmental defects $[42,43]$. Recently, Lehtinen et al. have shown that a major functional component of the cerebrospinal fluid that regulates telencephalic NSC proliferation and, thus, brain size is the IGF-2 signaling factor [44]. IGF-1 has been shown to promote NSC proliferation, and EGF, bFGF and IGF signaling cascades intersect to regulate NSC numbers in murine neurosphere cultures in vitro, in that IGF-1 and EGF cooperate to promote NSC renewal, while bFGF effects appear to be IGF-1 independent [45].

In the adult subependymal zone the relevance of the transforming growth factor (TGF)- $\alpha$ signaling for NSC proliferation has been demonstrated by TGF- $\alpha$ knockout mice. Moreover, intrastriatal TGF- $\alpha$ infusion in vivo could induce proliferation of adult neural progenitor cells and recruitment to the striatum [46]. TGF- $\alpha$ can also promote the reversion of mature astrocytes toward earlier neural progenitors [47]. While EGF/TGF- $\alpha$ family members may predominantly promote NSC expansion and proliferation, 


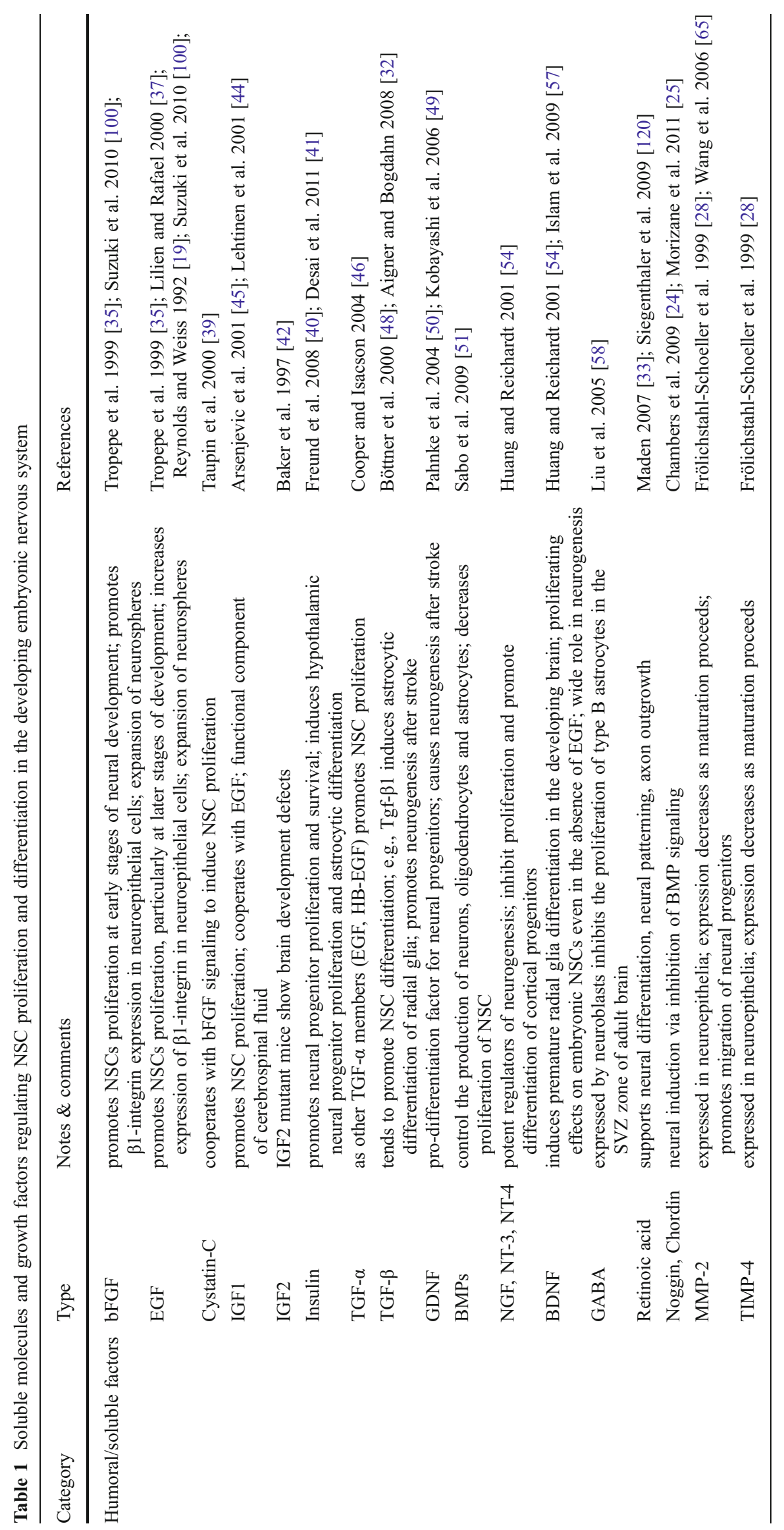




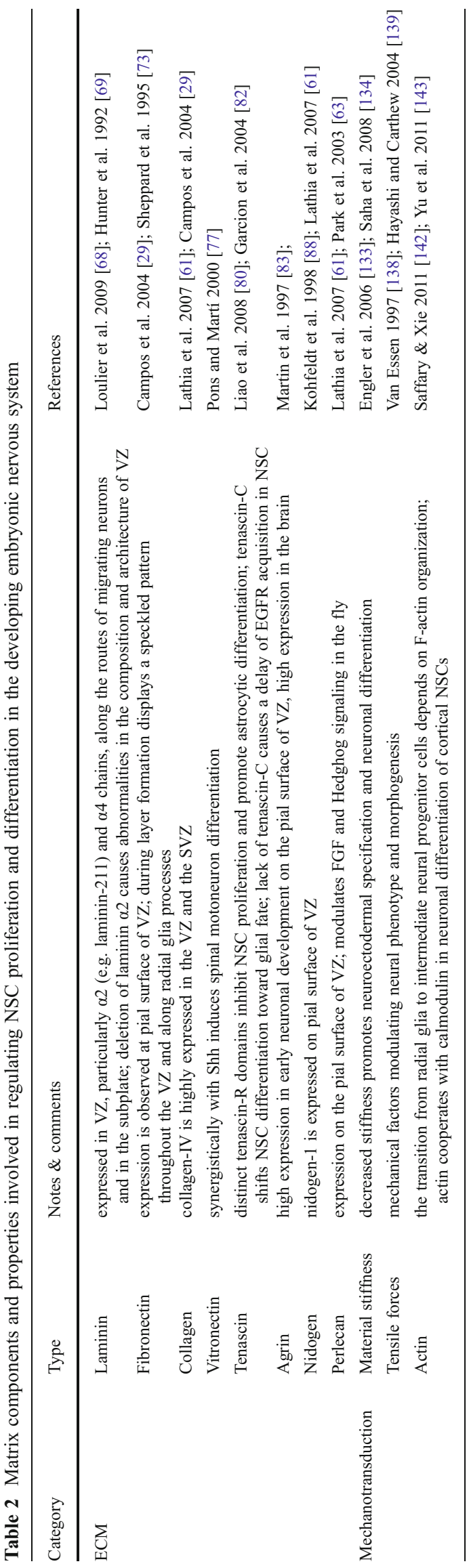

the TGF- $\beta$ family members may have anti-proliferative and pro-differentiating effects on NSCs and astrocytes. However, members of TGF- $\beta$ family may have a beneficial effect for neuronal survival after stroke and also promote neurogenesis $[32,48]$. Infusion of glial-derived neurotrophic factor (GDNF), a member of the TGF- $\beta$ family, into ischemic striatum promoted neurogenesis after stroke [49]. Overexpression of GDNF, particularly together with its receptor GFR $\alpha 1$, causes induction of genes responsible for differentiation of neural progenitor cells [50]. BMPs control the generation of neurons, astrocytes and oligodendrocytes and decrease the proliferation of embryonic and adult neural progenitors [51]. The BMPantagonist noggin was found to inhibit neurogenesis in neuroepithelium [52], whereas noggin expressed by ependymal cells of the adult mouse induced neurogenesis [53].

Signaling through members of the trk family of tyrosine kinase receptors, for example, neurotrophins such as nerve growth factor (NGF), brain-derived neurotrophic factor (BDNF), as well as the neurotrophin (NT)-3 and NT-4 are known as potent regulators of neurogenesis [54]. NT-3 inhibits proliferation of cortical precursors and enhances their differentiation [55]. Overexpression of BDNF in the adult rat brain enhanced olfactory and neostriatal neuronal recruitment [56]. BDNF maintains embryonic NSC proliferation through Erk, AKT and STAT3 pathways. In contrast, at the neurogenic stage, BDNF causes pre-mature differentiation of radial glia into astrocytes and glial precursors via activation of the MAPK-Erk pathway [57].

Finally, also diffusible neurotransmitters themselves can have an effect on the NSC niche: the neurotransmitter $\gamma$ aminobutyric acid (GABA) produced by neuroblasts in the adult SVZ inhibits the proliferation of type-B astrocytes, thereby creating a negative feedback loop [58]. While this paragraph exemplifies the fact that soluble factors are particularly potent modulators of NSC growth versus differentiation, mere supplementation of culture media with these factors is insufficient to fully control in vitro NSC development.

\section{ECM}

Interactions of cells with the ECM regulate NSC and neural precursor behavior and their integrity within the neurogenic niche $[59,60]$ (see Table 2). The ventricular zone (VZ) of the embryonic brain is in contact with the pial basal lamina that is often a hallmark of a stem cell niche. Moreover, basal lamina components such as laminins, nidogen- 1 , perlecan, collagen IV and agrin are found throughout the VZ and SVZ, with expression patterns changing both spatially and temporally [61-63]. While the adult neurogenic zone lacks a basal lamina, it is penetrated by blood vessels and contains fractones, basal lamina-like blood vessel extensions [59, 60]. Being rich in ECM components, these zones may provide important cues for both homeostatic and regenerative neurogenesis [11, 64]. 


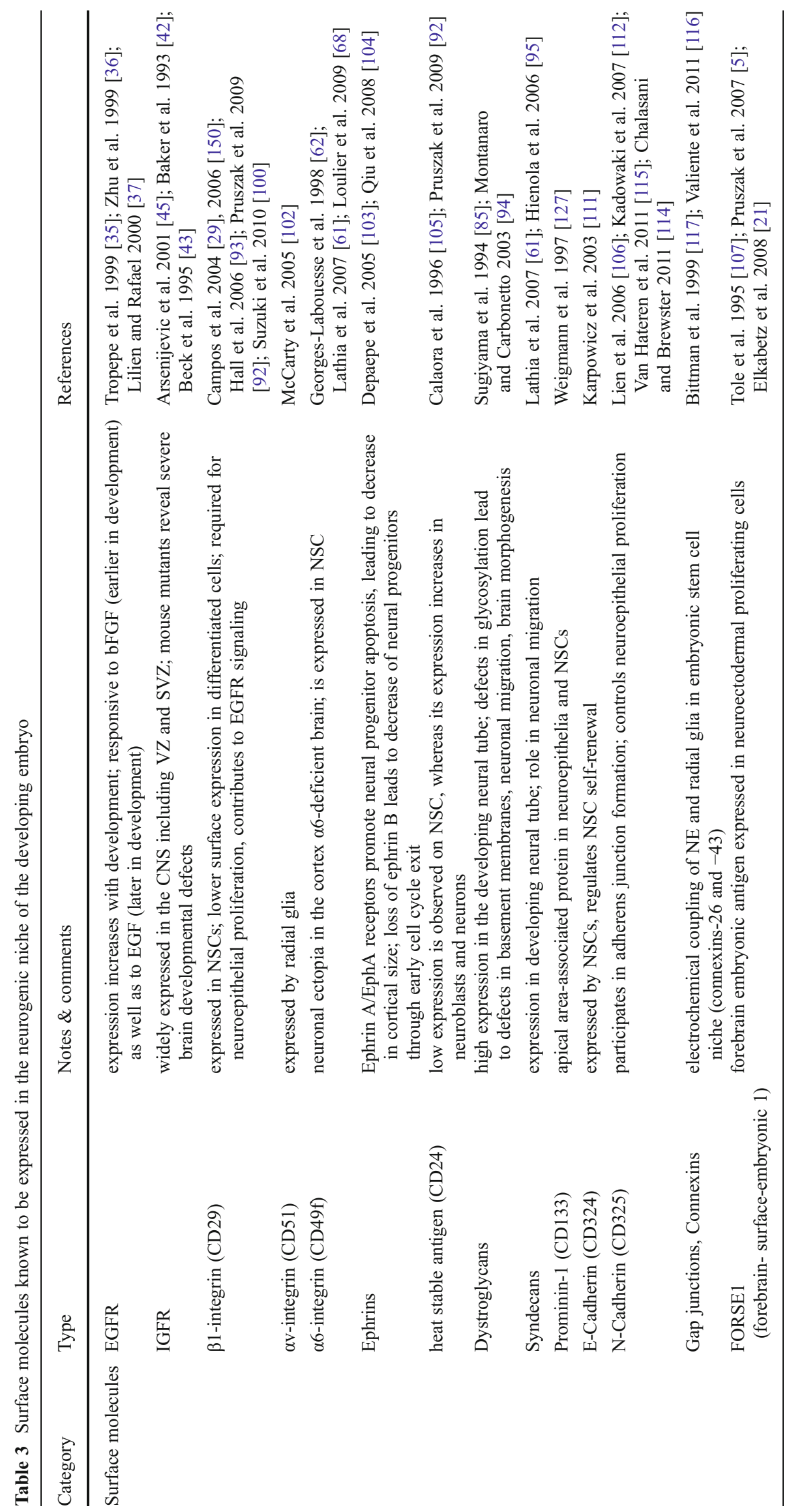


Importantly, ECM proteins can bind and release growth factors and cytokines and can themselves be proteolytically degraded [65], providing yet another mechanism of reciprocal stem cell niche regulation.

Laminins are large heterotrimeric glycoproteins comprised of $\alpha$-, $\beta$ - and $\gamma$-chains that represent a major constituent of the ECM. They play important roles in adhesion, migration, proliferation and differentiation. A number of laminin isoforms and glycoforms exist, some of which are indispensable for normal development. Others exhibit more specialized functions and their dysfunction causes defects in specific tissues and organs [66]. For example, the interaction between $\alpha 6 \beta 1-, \alpha 3$ b1-, $\alpha 6 \beta 4$-integrins and the laminin $\alpha 5$ chain is required for development of the limbs and lungs as well as for neural tube closure [67]. Laminins are present in many tissues of the nervous system [66]. In embryonic VZ development, $\alpha 2$ and $\alpha 4$ laminins are the most prominent subtypes [61]. With respect to the embryonic neurogenic niche, laminin expression, particularly expression of laminin-211 ( $\alpha 2 \beta 1 \gamma 1)$, appears to be critical for neurogenesis in the VZ of the developing CNS [60, 61, 64]. Deletion of the $\alpha 2$ laminin chain caused abnormalities in the architecture and composition of the embryonic mouse VZ, underlining the relevance of interactions of laminin $\alpha 2$ with corresponding cell surface receptors such as integrins to provide signals necessary for NSC adhesion, morphology and growth control [68]. Furthermore, laminin is expressed as a substrate for neuronal migration, among others in the neural subplate, providing a scaffold for migrating neuroblasts [69].

Fibronectin is another abundant and ubiquitous glycoprotein of the ECM that affects cellular adhesion, migration, proliferation and differentiation [70]. Fibronectinimmunoreactivity appears at the blastocyst stage of mammalian embryos [71] and its deletion results in early embryonic lethality in the mouse. Heterozygous animals exhibit mesodermal defects, aberrant neural tube formation and impaired vascular development [72]. In the early pseudostratified neuroepithelia, fibronectin is seen on the pial surface of the cells [61]. Upon formation of the cortical plate, fibronectin is found at low levels in the ventricular and subventricular areas, an expression pattern which is maintained postnatally as well [29]. During cortical layer formation fibronectin is expressed by radial glia, migrating neurons and cortical neurons [73]. In vitro, it is commonly used as a substrate component of PSC neural differentiation protocols.

Collagens are a family of triple-helical proteins that provide a scaffold for the ECM and basement membrane stability. The collagen isoform $\alpha 2$ is present in the basal lamina of neuromuscular junctions and mediates early clustering of synaptic vesicles [74]. Other collagen isoforms, $\alpha 3$ and $\alpha 6$, participate in the maturation and maintenance of motor nerve terminals. In the $\mathrm{VZ}$ and $\mathrm{SVZ}$ as well as in the intermediate zone collagen-IV is highly present and its expression pattern changes while development proceeds, thereby implying a role in neurogenesis and migration [61]. Collagens-I and -IV are also present in fractones of the adult SVZ [59, 60].

Other components of extracellular matrix are also important for a cell's interaction with the stem cell niche, again largely via integrin surface molecules. Martínez-Morales et al. showed that vitronectin is expressed in the ventral region of the neural tube and promotes differentiation of neuroepithelium to motor neurons in chick embryo in vivo and in vitro [75]. Vitronectin binds cells through integrins containing the $\alpha v$-subunit. Conversely, integrins recognize the arginine-glycine-aspartate (RGD) motif on vitronectin [76]. Pons and Martí showed that sonic hedgehog can synergize with vitronectin to induce spinal motor neuron differentiation [77]. Moreover, it has been suggested that vitronectin and its receptor $\alpha \mathrm{v} \beta 5$-integrin are important for the elongation of parallel fibers in the cerebellum [78]. Tenascins are large extracellular glycoproteins. In human there are four members of the tenascin family: tenascin-C, $\mathrm{R},-\mathrm{W}$ and $-\mathrm{Y}[79,80]$. Tenascins have also been detected in both peripheral and central nervous system. Microinjection of antibodies against tenascin-C inhibits migration of neural crest cells in the head of avian embryos [81]. Importantly, tenascin-C knockout mice display impaired NSC development which has been linked to the function of tenascin-C to promote EGFR surface expression of NSCs [82]. Also, multiple agrin isoforms are found in the brain neural tissue and micro-vasculature, which implies a role of the agrin molecule and its cellular receptors in the nervous system and its development. Agrin receptors include $\alpha \mathrm{v} \beta 1$-integrin [83], but also the neural cell adhesion molecule (NCAM, CD56) [84], $\alpha$-dystroglycan [85], neuregulins [86] and others. Nidogens represent another glycoprotein member of basement membrane components [87], interacting with various basement membrane components such as collagenIV and laminin. Integrins $\alpha \mathrm{v} \beta 3$ and $\alpha 3 \beta 1$ are receptors for nidogen-1, as RGD peptide as well as corresponding blocking antibodies impair cell adhesion on nidogen-1 [88]. Chondroitin sulfate proteoglycans play an important role in the fusion of neural folds upon neural tube morphogenesis [89].

\section{ECM-Cell Interactions}

The cellular receptors for a number of neuroembryological ECM molecules including laminins, collagens, fibronectin and vitronectin comprise the integrin family of surface receptors (see Table 3 ). $\beta 1$-integrin expression occurs early during embryonic development $[90,91]$ and, in a variety of tissues, $\beta 1$-integrin signaling is necessary for stem cell selfrenewal. Moreover, $\beta 1$-integrin, the CD29 surface antigen, is highly expressed in NSCs of the VZ in the developing 
brain $[29,61]$ and marks proliferating NSCs derived from primary tissue as well as from PSCs [29, 92, 93]. In more differentiated cells types, $\beta 1$-integrin expression fades and is low or absent in doublecortin-positive neuroblasts [92] and $\beta$-III-tubulin-positive cells, respectively [29]. In addition to integrins, receptors for laminins present on NSCs include dystroglycans and syndecans. They are expressed in neuron-containing regions of developing neural tube and regulate neural adhesion and migration $[61,94,95]$. Within the integrin family of surface receptors, the $\beta 1$-subunit plays a central role, forming the greatest range of $\alpha \beta$-heterodimers. In mouse and human neurospheres $\beta 1$-integrin expressing cells are observed only at the edge of the spheres, together with nestin, EGFR and laminin- $\alpha 2$. $\beta$-III-tubulin-positive areas exist in the center of the neurosphere, and do not express $\beta 1$-integrin $[29,93]$. Consistent with that, fluorescence-activated cell sorting revealed that $\beta 1$-integrin high $\left(\mathrm{CD} 29^{\text {high }}\right)$ human neural cells express NSC marker mRNAs, including prominin-1 (CD133), nestin, sox 2 , musashi- 1 and bmi- 1 . In contrast, $\beta 1$-integrin low $\left(\mathrm{CD} 29^{\text {low }}\right)$ cells express higher levels of $\beta$-III-tubulin [92, 93]. Implication of $\beta 1$-integrin in survival, self-renewal and proliferation of NSCs has been robustly established. Co-expression of the $\alpha 6$-subunit (CD49f) with $\beta 1$-integrin has been observed in NSCs, for instance, in the VZ area in vivo as well as at the outer edge of neurospheres [11, 29]. Integrin heterodimers of particular functional relevance for neural development and regulation of the NSC niche include $\alpha 6 \beta 1-[11,29], \alpha 3 \beta 1-$ and $\alpha v \beta 1$ - heterodimers [96, 97]. Long-term blockage of ECM-cell interactions via integrins has been shown to lead to abnormalities in postnatal cortex layering [62] (reviewed in [98]). Although $\beta 1$-integrin blockage in the VZ did not alter NSC differentiation, it resulted in apical detachment of radial glia cells and affected their bipolar morphology [68]. Subsequent neuronal migration and cortex development were also affected. $\beta 1$ integrin-neutralizing antibodies infused to the lateral ventricle of 8-week old animals greatly decreased the number of neural precursor cells [99]. Consistent with that finding, $\beta 1$-integrin knockdown in neuroepithelial cells in vitro has also been shown to cause a change in cell morphology, especially significant in cells grown with EGF on fibronectin-coated dishes [100]. $\beta 1$-integrin loss impairs adhesion of neurospheres from postnatal mouse brain on laminin and to a lesser extent on fibronectin [101], which may reflect the possibility that fibronectin adhesion is induced by integrins present in NSCs other than $\beta 1$-integrin, such as $\alpha v \beta 5$ and $\alpha v \beta 8$ [93, 97]. In vitro proliferation of neural precursors (nestin-positive, GFAP-negative) from postnatal brain on fibronectin is partly induced by $\beta 1$-integrin, $\alpha 5 \beta 1$ or $\alpha \mathrm{v} \beta 1$. Laminin also induces proliferation of these cells, through $\beta 1$-integrindependent mechanisms [29, 97].

\section{Cell-Cell Interactions}

A broad spectrum of additional surface molecules is expressed during neural development as well as in the adult neurogenic niches and already known to be important for NSC regulation (see Table 3) [102-107]. Others remain to be studied with respect to their functional relevance. The glycan CD15 antigen (SSEA-1, Lewis-X-antigen; fucose $\mathrm{N}$-acetyl lactosamine) is expressed in adult mouse neurogenic regions on type-B and -C cells of the SVZ as well is in the hippocampus and has been shown to contribute to neurogenic niche maintenance and NSC proliferation [108]. CD15 is also expressed on embryonic neuroepithelia [109], and has also been identified to label NSCs during in vitro neural differentiation of human PSCs [92]. Galectin1 , a lectin expressed by adult NSCs promotes proliferation of NSCs in the SVZ as well as in the hippocampal dentate gyrus in the mouse, a regulatory function requiring the interaction of galectin- 1 with $\beta 1$-integrin subunit on NSCs [97]. For some of these surface molecules, potent inducers have long been known, such as fucosyltransferases for expression of the CD15 epitope. Moreover, detailed insights into modulation of these glycan moieties, e.g. through sialidases have recently been gained [110]. Cadherins, a class of cell-adhesion and signaling proteins, are another group of surface molecules present on NSCs in the neurogenic zone. E-cadherin is expressed in ventricular areas of both embryonic and adult brain by NSCs and regulates self-renewal [111]. N-cadherin is necessary for the formation of adherens junctions in mouse neuroepithelial and radial glia cells and disruption of $\mathrm{N}$-cadherin function causes defects in cortical organization [112, 113]. Depending on the cellular context, $\mathrm{N}$-cadherin-dependent adhesion can either promote or inhibit proliferation of neural progenitors [114, 115]. Electrochemically, neural cells in the VZ interact with one another already during development by gap junctional intercellular coupling, probably via connexins- 26 and $-43[116,117]$. Continued investigation of the regulatory mechanisms controlling expression and function of surface molecules that developing cells use to interact with one another and with adjacent cell populations is undoubtedly warranted. It is known that during neural induction, interactions with the underlying mesoderm take place, for example, by repression of BMP activity through mesodermal factors such as chordin. Analogously to that, stromal feeder cells have been exploited for neural induction of PSCs [118, 119]. Later in development, interactions with the overlaying meningeal tissues appear to be important for appropriate neuroepithelial development [120]. While insights into the precise nature of such cell-cell interactions during embryologic neuroepithelial development are still limited, we have gained considerable insight into the interaction of adult NSCs with their neighbors. For example, type B cells 
(NSCs) extend a process through the ependymal layer to contact the ventricle and some cells intercalate between ependymal cells $[11,121]$, and data suggests that ependymal cells modulate neurogenesis via signaling factors such as Noggin, pigment epithelium-derived factor (PEDF) and others [53, 122]. Both the SVZ as well as the hippocampal subgranular zone of adult brain are highly vascularized [11, 64]. Type $B$ and type $C$ (transit- amplifying precursor) cells locate closely to blood vessels, often contacting them, whereas neuroblasts (type A cells) locate more distal from vasculature [11, 123]. Some type B cells contact both a blood vessel and a ventricle, thereby having access to ependymal or ventricular factors (cerebrospinal fluid) and endothelial factors [11]. While this is a field of ongoing investigation, neural progenitors in the SVZ of the embryo locate and divide in close proximity to capillary branches, and embryonic vasculature in the VZ appears to be vital for the neurogenic niche and for embryonic brain development [124]. Similarly, in the adult brain cell adhesion to blood vessels in SVZ appears to be $\beta 1$-integrin-dependent. Infusion of the $\alpha 6$-antibody $\mathrm{GoH} 3$ to the lateral ventricle of mouse brain causes detachment of NSC from the vascular surface [11], and association with blood vessels can be enhanced by activating quiescent NSCs toward cell cycle reentry, which is correlated with increased $\beta 1$-integrin expression [64]. Neuroblasts (neuronal precursors or type A cells) migrating tangentially via the rostral migratory stream to the olfactory bulbs to form interneurons are ensheathed by astroglia [125], secreting factors that are likely to promote the process of migration. Thus, cellular interactions with neural progeny from the stem cells themselves and other immediate neighbors such as vascular, ependymal cells and glial cells play an essential role in maintaining the critical balance of proliferation versus differentiation in NSC niches.

\section{Supracellular Context, Cellular Orientation and Polarity}

For in vitro differentiation of PSCs, we routinely apply complex combinations of growth and patterning factors and supply appropriate recombinant or synthetic substrates modeled after embryonic ECMs in a sequence and time frame largely equivalent to embryological development. What is lacking is a detailed understanding of how cellcell communication and interdependent structural organization (cell and tissue morphogenesis) contribute to NSC development in vivo as well as in vitro. The above humoral factors, ECM components and surface molecules enable a cell to sense (and modulate its interaction with) its immediate environment, and its position and proper orientation within it. Extending between the basal and pial surfaces of the germinal layer, embryonic neuroepithelia display a polarized character, an asymmetric distribution of cytoplasmic as well as membrane-bound structures and organelles (apico-basal polarity). For instance, cadherinassociated adherens junction complexes, tend to localize toward the apical surface [126]. On the surface of neuroepithelial cells, apical area-associated proteins including prominin-1 [127], cdc42 and PAR3/PAR6/aPKC complexes have been identified [13]. As previously indicated, the apico-lateral membrane of neuroepithelial cells is also rich in $\alpha 6 \beta 1$-integrin, and localization of $\beta 1$-integrin complexes has been observed apico-laterally, associated with adherent junctions $[61,68]$. Such asymmetrical $\beta 1$-integrin distribution on the membrane enables the unequal inheritance by daughter cells [61]. Importantly, the apico-basal polarity of neuroepithelial cells and radial glia forms the basis for the switch between asymmetrical and symmetrical cellular divisions [126]. Vertical cleavage planes bisecting the apical surface result in symmetric cell division. Horizontal cleavage causes unequal partitioning of cellular components and thereby asymmetric inheritance $[128,129]$. As unequal distribution of $\beta 1$-integrin between daughter cells has been observed, $\beta 1$-integrin might be spread unequally in daughter NSC and progenitor cell depending on mitotic spindle orientation and its own membrane distribution [61]. Blocking the interaction of the ECM with $\beta 1$-integrin alters NSC cleavage plane orientation in the embryonic brain, and fewer divisions were observed with horizontal cleavage planes [68]. Whether this is caused by cell detachment from the apical surface of the lateral ventricle or absence of $\beta 1$ integrin signaling itself has not been entirely clarified. Detachment from the neurogenic niche is one consequence of diminishing the ECM-integrin connection [11, 64, 68]. Loss of contact may change the position of the NSCs or neural precursors, thereby leading to differential exposures of daughter cells to various extracellular factors. Laminin- $\gamma 1$ mutant zebrafish reveal abberant interkinetic nuclear migration, basal dislocation of mitotic nuclei in neuroepithelia and randomized cleavage planes mediated through focal adhesion kinase (FAK) activation, proposing a putative role of integrins in neuroepithelial cytokinesis [130]. Potentially, integrins regulate mitotic spindle organization in mammalian neuroepithelia, as $\beta 1$-integrin is known to regulate mitotic spindle assembly and cytokinesis in Chinese hamster ovary (CHO) cells [131] and regulation of spindle orientation by integrinmediated adhesion in epithelial cells and in HELA cells has been shown [132].

Thus, as in the embryo, neural stem and progenitor cells undergoing differentiation in the dish base their fate decisions on the context of appropriate growth factor concentrations, ECM interactions and on cell-cell signaling. Furthermore, cell density is a factor empirically taken into consideration but still rather poorly understood. In a now classic paper by Tropepe et al., 1999, an influence of cell density on the generation of primary tissue-derived NSCs 
was observed: EGF-mediated mitogenic effects were more profound under high density plating conditions (as opposed to bFGF-mediated mitogenic effects) [35]. The influence of cell-cell interactions on PSC neural differentiation pathways was recently implied empirically, as high density cultures of PSCs undergoing neural differentiation tend to generate CNS-neuronal derivatives, while lower density conditions seem to favor neural crest development [24]. At the stage of pluripotency, substrate stiffness has a profound effect on cell fate decision; enhanced matrix stiffness resulting in mesodermal offspring, while decreasing stiffness has been shown to promote neuroectodermal lineage specification [133]. At more committed stages, NSCs show a propensity toward neuronal differentiation on softer substrates $(100$ $500 \mathrm{~Pa}$ ), while glial differentiation is promoted at higher stiffness conditions (e.g., 10,000 Pa) [134]. Hypothetical pathways involved in sensing the extracellular conditions with respect to cell density could include signaling mechanisms related to contact inhibition and growth control (Hippo pathway) [135-137] and integrin signaling, respectively. Tensile forces and ECM-integrin-mediated anchoring can lead to direct activation of integrin pathways via FAK, She and other downstream signaling cascades [116, 138, 139]. In addition, via direct linkage to cytoskeletal components integrin and cadherin signaling can also lead to modulation of a variety of actin-regulated and other mechanotransductory pathways [140-143].

\section{Integration of the Signaling Pathways}

In the previous sections, we have illustrated the critical relevance of growth factor signaling, of ECM molecules, the integrin family of cell receptors and other surface molecules as well as recently identified mechanisms of polarity, mechanotransduction and cell density-dependent signaling for the phenomena of NSC growth control and differentiation. How do these extrinsic factors get translated to cell fate decisions? What are the underlying intracellular signaling mechanisms and how could they be integrated for appropriate control of growth versus differentiation?

It is sensible to hone in on pathways that are differentially affected by the interplay of the above components of the NSC niche (see Fig. 2; Table 4). For example, bFGF and EGF are both able to increase $\beta 1$-integrin expression in mouse neuroepithelial cells [100], yet bFGF has a more prominent effect on $\beta 1$-integrin gene expression than EGF, whereas stimulation by EGF increases cell surface localization of $\beta 1$-integrin. Treatment with MAPK pathway inhibitors decreases the level of $\beta 1$-integrin in neuroepithelial cells grown in bFGF or EGF in a dose-dependent manner, underlining the involvement of MAPK pathway signaling in EGF- or bFGF-stimulation of $\beta 1$-integrin expression [100,
144]. Similarly, $\beta 1$-integrin expression in the neurospheres from postnatal mouse brain is higher in the presence of EGF than of bFGF. Interestingly, bFGF, in contrast to EGF, strongly induces EGFR expression in neurospheres [29, 101]. Cells expressing high levels of $\beta 1$-integrin form more neurospheres and this effect is more prominent for EGFgrown neurospheres than for bFGF-grown neurospheres $[29,93]$. Data obtained suggest that proliferation control by $\beta 1$-integrin occurs through regulation of MAPK signaling, since genetic deletion or antibody blocking of $\beta 1$ integrin in neurospheres grown in the presence of bFGF and EGF leads to a decrease in MAPK activation and cell proliferation [29, 100]. Subsequent passaging of neurospheres restores normal level of MAPK activation, which implies the presence of alternative pathways to substitute the lack of $\beta 1$-integrin [29]. Similarly, in vitro knockdown of $\beta 1$-integrin in mouse neuroepithelial cells also results in decreased proliferation in the presence of $\mathrm{bFGF}$ or EGF [100]. However, deletion of $\beta 1$-integrin in conditional knockout experiments did not reveal abnormalities in the VZ [145]. Nevertheless, presence of laminins and $\beta 1$ integrin in the $\mathrm{VZ}$ of developing mouse brain $[29,61]$ may suggest that interaction between them is important for NSCs and long-term absence of them could be compensated. EGFand bFGF-driven neurospheres isolated from rat postnatal brain with $\beta 1$-integrin deletion are smaller in size compared to wild-type neurospheres, while the amount of formed neurospheres is not affected by lack of $\beta 1$-integrin [101]. Mutant neurospheres have a lower percentage of nestinpositive cells and a higher percentage GFAP-positive and $\beta$-III-tubulin-positive cells. Both increased apoptosis and reduced proliferation of nestin-positive progenitor cells were observed in $\beta 1$-integrin-deficient neurospheres. The authors demonstrated that $\beta 1$-deficiency sensitizes neurospheres to the lack of growth factors EGF and bFGF, although maintenance of progenitors was not affected by the absence of $\beta 1$ integrin when cells were grown together with EGF and bFGF [101]. It has been shown as well that Erk 1/2 activation promotes proliferation and inhibits neuronal differentiation of NSC [146, 147] and Erk is known to be a molecule that can be affected by $\beta 1$-integrin signaling, though integrins are not the only activators of the Erk pathway. Thus, an important triad of integratory signals appears to be the balance of EGF and bFGF signals with $\beta 1$-integrin and downstream MAPK signaling as one potential converging signaling pathway.

Notch signaling represents another important signaling pathway for stem cell niche regulation, including in the nervous system, controlling NSC maintenance as well as neuronal/glial fate decisions [148, 149]. $\beta 1$-integrindependent control of NSC proliferation is partially also mediated by Notch signaling [150]. $\beta 1$-integrin and Notch are both co-expressed in VZ and in neurospheres. $\beta 1$ integrin interacts with the Notch intracellular domain 
Fig. 2 Schematic exemplifying major pathways and signaling components involved in embryonic NSC proliferation and differentiation. Cell-matrix and cell-cell interactions cooperate with tissue gradients of diffusible molecules and secreted factors from the CSF. Cdc42 and MAPK-Erk signals represent key pathways able to integrate growth factor-derived signaling (EGF, bFGF, IGFs) with adhesion and mechanotransductory signaling mediated by cadherins and integrins. Nuclear downstream factors such as myc, Hes5, Pax6, Id4 exemplify transcriptional regulators of NSC self-renewal

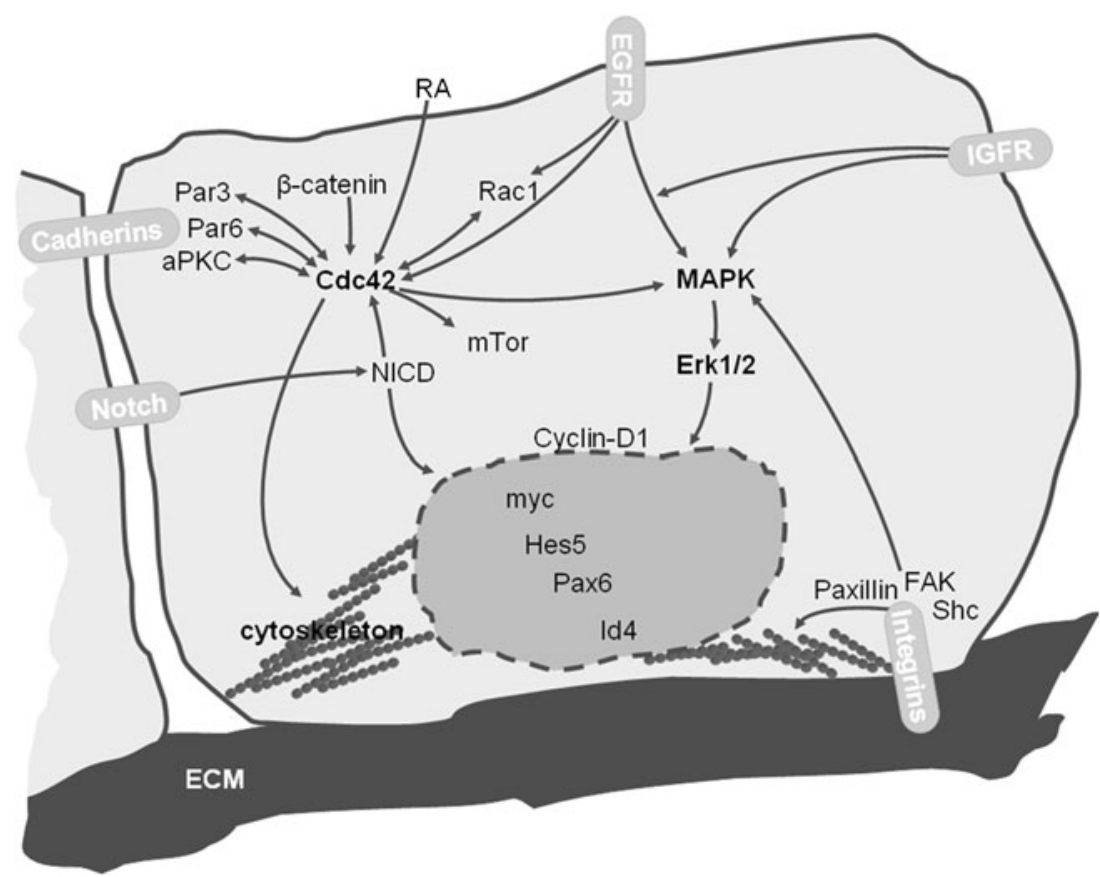

(NICD) and may modulate NICD nuclear/membrane distribution depending on the active/inactive state of $\beta 1$-integrin. Coordination of $\beta 1$-integrin and EGFR is required for NICD internalization from caveolae-positive lipid raft domains to non-raft domains in mouse neurospheres and ES cells-derived NSCs. Loss of $\beta 1$-integrin results in decreased Notch processing and prevents its downstream proliferative activities, thereby decreasing neurosphere formation. Since Notch is required for the successive generation of neurons and glia, the study of Campos and colleagues reveals a potential way of $\beta 1$-integrin control in radial glial/neuronal differentiation of NSC through the modulation of Notch signaling [150]. PEDF secreted by ependymal cells and endothelial structures in the adult SVZ has been shown to maintain self-renewal and multipotency of NSCs by increasing expression of the Notch pathway effectors Hes-1 and -5 as well as of Sox2 [122].

Members of the Rho family of guanosine triphosphate (GTP)ases are additional players in control of neural progenitors. They interpret an array of upstream signals including those emanating from integrin activation [151], and regulate the cytoskeleton, proliferation and apoptosis, interacting with and integrating mechanosensory and morphogenetic pathways [152]. In embryonic mammalian neural progenitors, Rac1-deficiency can cause apoptosis and cell cycle exit, resulting in diminishing NSC pools [153]. Moreover, the closely associated GTPase cdc42 controls NSC renewal in the developing forebrain [154]. Deletion of cdc42 accompanied by loss of apical complex and adherens junctions results in loss of self-renewal, i.e. of maintenance of an NSC, and enhanced generation of neuroblasts. Eventually, the NSC pool is prematurely depleted in cdc42 knockout mice. Conversely, stimulating cdc42 signaling may help to recruit NSCs from adult neurogenic areas. Upstream of cdc42, links to the aforementioned cadherin and integrin molecules are clear, as cdc42 is linked to adhesion as well as to polarity. Other upstream factors include retinoic acid, as well as delta/Notch signaling, and links to mammalian target of rapamycin (mTOR) signaling have also been recently suggested [155]. In P19 multipotent embryonic carcinoma cells, Endo et al. have shown that cdc42 can induce Hes-5 and Pax6 gene expression [156], and basic helix-loop-helix (bHLH) family members are powerful regulators of NSC proliferation versus differentiation on a transcriptional level [157]. Hes-1 and Hes-5, are required for NSC self-renewal [158]. Pax6, highly expressed in neurogenic niches, is a multifunctional transcription factor, essential for both embryonic and adult neurogenesis. It is involved in neural tube patterning, neuronal migration and formation of neural circuits [159]. Correspondingly, the group of inhibitors of DNA binding (Id) proteins has been implicated in NSC regulation as dominant-negative regulators of bHLH factors [160, 161]. For example, Id4-/- mice show a smaller telencephalon [162]. Interestingly, Id proteins, in turn, seem to be able to regulate adherence to the neural stem cell niche by maintaining high levels of RAP1 as a positive modulator of integrins [163]. In addition to such anchoring and to intercellular signals, the decision of NSCs whether to proliferate or differentiate ultimately converges on the level of cell cycle regulation. The Myc family of transcription factors, potent cell cycle regulators, are also involved in fundamental developmental processes in the nervous system [164, 165]. Myc is essential for the rapid expansion of neural 
progenitors and regulates differentiation. Via modulation of cell cycle components such as cyclin D1, p16Ink4a or p21CIP1 myc (and also Id proteins) are thought to execute an inhibitory function on differentiation [166]. There is a line of evidence suggesting that lengthening the cell cycle without arrest triggers differentiation [167, 168]. $\beta 1$ integrin and EGFR are both required for full activation of MAPK signaling and proliferation and can influence the cell cycle, and asymmetric surface distribution of EGFR and resulting divergence of cell fates has been demonstrated [169]. Since $\beta 1$-integrin is able to synergize with EGFR and Notch signaling to induce proliferation $[29,100,150]$, unequal partitioning of these and other receptors or signaling components may differentially affect cell cycle progression and differentiation of the generated neural progeny.

\section{Conclusions and Summary}

The embryonic neurogenic niche is represented by a complex and well-orchestrated network of intercellular cues such as growth and other soluble factors, ECM components and surface molecules which jointly control NSC renewal and fate specification. By taking advantage of human PSC in vitro differentiation, fundamental mechanisms of basic human neuroembryology and NSC regulation can for the first time be studied and modulated in accessible and controllable experimental systems. Combined with insights from rodent studies, this may eventually contribute to enabling future in vivo recruitment of neurons from the human NSC niche in the adult [46]. In the immediate future, efforts that take into account all parameters guiding cellular decisions in the NSC niche will likely yield more appropriate neural differentiation protocols from human PSCs. Given the extended duration of the differentiation protocols (weeks to months), fine-tuning the concentrations and time frame of combinatorial exposure to growth and patterning factors will remain essential $[6,24]$. In addition, beyond commonly applied purified ECM substrates, a range of recombinant or novel synthetic substrates will further enhance NSC culture specificity and standardization $[10,170]$. Micro-/nano-patterned surfaces or 3D scaffolds modified to provide bioactive peptides for anchoring, options for electrochemical modulation and mechanical cues will contribute to mimicking the physical aspects of the physiological NSC niche $[134,141,170]$. Extended characterization of specific neural surface marker signatures will not only be exploited to select and isolate specific subsets of biomedical interest, but will also contribute to enhancing our understanding of the functional relevance of these molecules for intercellular signaling [21, 92]. While still far from understanding the intricacies of neural morphogenesis, more organotypic complex 3D PSC differentiation systems have already successfully been 
applied [171]. Taken together, regardless of the remaining challenges, the convergence of efforts ranging from fundamental cell biology to bioengineering holds great promise for the generation of more physiologically patterned neural cell types from human stem cells.

Acknowledgments Research funding through the Emmy Noether Program of the German Research Foundation (DFG), Germany, is gratefully acknowledged.

Conflicts of interest The authors declare no potential conflicts of interest.

Open Access This article is distributed under the terms of the Creative Commons Attribution License which permits any use, distribution, and reproduction in any medium, provided the original author(s) and the source are credited.

\section{References}

1. Thomson, J. A., Itskovitz-Eldor, J., Shapiro, S. S., et al. (1998). Embryonic stem cell lines derived from human blastocysts. Science, 282(5391), 1145-1147.

2. Takahashi, K., \& Yamanaka, S. (2006). Induction of pluripotent stem cells from mouse embryonic and adult fibroblast cultures by defined factors. Cell, 126(4), 663-676.

3. Lerou, P. H., \& Daley, G. Q. (2005). Therapeutic potential of embryonic stem cells. Blood Reviews, 19(6), 321-331.

4. Nishikawa, S., Goldstein, R. A., \& Nierras, C. R. (2008). The promise of human induced pluripotent stem cells for research and therapy. Nature Reviews Molecular Cell Biology, 9(9), 725-729.

5. Pruszak, J., Sonntag, K.-C., Aung, M. H., Sanchez-Pernaute, R., \& Isacson, O. (2007). Markers and methods for cell sorting of human embryonic stem cell-derived neural cell populations. Stem Cells, 25(9), 2257-2268.

6. Pruszak, J., \& Isacson, O. (2009). Molecular and cellular determinants for generating ES-cell derived dopamine neurons for cell therapy. Advances in Experimental Medicine and Biology, 651, $112-123$.

7. Itskovitz-Eldor, J. (2011). A panel of glycan cell surface markers define pluripotency state and promote safer cell-based therapies. Cell Stem Cell, 9(4), 291-292.

8. Carson, C. T., Aigner, S., \& Gage, F. H. (2006). Stem cells: the good, bad and barely in control. Nature Medicine, 12(11), 12371238 .

9. Schofield, R. (1978). The relationship between the spleen colonyforming cell and the haemopoietic stem cell. Blood Cells, 4(1-2), $7-25$

10. Keung, A. J., Kumar, S., \& Schaffer, D. V. (2010). Presentation counts: microenvironmental regulation of stem cells by biophysical and material cues. Annual Review of Cell and Developmental Biology, 26, 533-556.

11. Shen, Q., Wang, Y., Kokovay, E., et al. (2008). Adult SVZ stem cells lie in a vascular niche: a quantitative analysis of niche cellcell interactions. Cell Stem Cell, 3(3), 289-300.

12. Sauer, F. (1935). Mitosis in the neural tube. The Journal of Comparative Neurology, 62(2), 377-405.

13. Götz, M., \& Huttner, W. B. (2005). The cell biology of neurogenesis. Nature Reviews Molecular Cell Biology, 6(10), 777-788.

14. Caviness, V. S., Jr., Goto, T., Tarui, T., Takahashi, T., Bhide, P. G., \& Nowakowski, R. S. (2003). Cell output, cell cycle duration and neuronal specification: a model of integrated mechanisms of the neocortical proliferative process. Cerebral Cortex, 13(6), 592-598.

15. Rakic, P. (2003). Developmental and evolutionary adaptations of cortical radial glia. Cerebral Cortex, 13(6), 541-549.

16. Luskin, M. B. (1993). Restricted proliferation and migration of postnatally generated neurons derived from the forebrain subventricular zone. Neuron, 11(1), 173-189.

17. Alvarez-Buylla, A., \& Lim, D. A. (2004). For the long run: maintaining germinal niches in the adult brain. Neuron, 41(5), 683-686.

18. Ming, G.-L., \& Song, H. (2011). Adult neurogenesis in the mammalian brain: significant answers and significant questions. Neuron, 70(4), 687-702.

19. Reynolds, B. A., \& Weiss, S. (1992). Generation of neurons and astrocytes from isolated cells of the adult mammalian central nervous system. Science, 255(5052), 1707-1710.

20. Takahashi, K., Tanabe, K., Ohnuki, M., et al. (2007). Induction of pluripotent stem cells from adult human fibroblasts by defined factors. Cell, 131(5), 861-872.

21. Elkabetz, Y., Panagiotakos, G., Al Shamy, G., Socci, N. D., Tabar, V., \& Studer, L. (2008). Human ES cell-derived neural rosettes reveal a functionally distinct early neural stem cell stage. Genes \& Development, 22(2), 152-165.

22. Roy, N. S., Cleren, C., Singh, S. K., Yang, L., Beal, M. F., \& Goldman, S. A. (2006). Functional engraftment of human ES cell-derived dopaminergic neurons enriched by coculture with telomerase-immortalized midbrain astrocytes. Nature Medicine, 12(11), 1259-1268.

23. Li, X.-J., Du, Z.-W., Zarnowska, E. D., et al. (2005). Specification of motoneurons from human embryonic stem cells. Nature Biotechnology, 23(2), 215-221.

24. Chambers, S. M., Fasano, C. A., Papapetrou, E. P., Tomishima, M., Sadelain, M., \& Studer, L. (2009). Highly efficient neural conversion of human ES and iPS cells by dual inhibition of SMAD signaling. Nature Biotechnology, $27(3), 275-280$.

25. Morizane, A., Doi, D., Kikuchi, T., Nishimura, K., \& Takahashi, J. (2011). Small-molecule inhibitors of bone morphogenic protein and activin/nodal signals promote highly efficient neural induction from human pluripotent stem cells. Journal of Neuroscience Research, 89(2), 117-126.

26. Reynolds, B. A., \& Weiss, S. (1996). Clonal and population analyses demonstrate that an EGF-responsive mammalian embryonic CNS precursor is a stem cell. Developmental Biology, 175(1), 1-13.

27. Lobo, M. V. T., Alonso, F. J. M., Redondo, C., et al. (2003). Cellular characterization of epidermal growth factor-expanded free-floating neurospheres. Journal of Histochemistry and Cytochemistry, 51(1), 89-103.

28. Frölichsthal-Schoeller, P., Vescovi, A. L., Krekoski, C. A., Murphy, G., Edwards, D. R., \& Forsyth, P. (1999). Expression and modulation of matrix metalloproteinase-2 and tissue inhibitors of metalloproteinases in human embryonic CNS stem cells. Neuroreport, 10(2), 345-351.

29. Campos, L. S., Leone, D. P., Relvas, J. B., et al. (2004). Beta1 integrins activate a MAPK signalling pathway in neural stem cells that contributes to their maintenance. Development, 131 (14), 3433-3444.

30. Lin, G., Wu, V. I., Hainley, R. E., Flanagan, L. A., Monuki, E. S., \& Tang, W. C. (2004). Development of a MEMS microsystem to study the effect of mechanical tension on cerebral cortex neurogenesis. Conference Proceedings - IEEE Engineering in Medicine and Biology Society, 4, 2607-2610.

31. Abematsu, M., Smith, I., \& Nakashima, K. (2006). Mechanisms of neural stem cell fate determination: extracellular cues and intracellular programs. Current Stem Cell Research \& Therapy, 1(2), 267-277. 
32. Aigner, L., \& Bogdahn, U. (2008). TGF-beta in neural stem cells and in tumors of the central nervous system. Cell and Tissue Research, 331(1), 225-241.

33. Maden, M. (2007). Retinoic acid in the development, regeneration and maintenance of the nervous system. Nature Reviews Neuroscience, 8(10), 755-765.

34. Moyse, E., Segura, S., Liard, O., Mahaut, S., \& Mechawar, N. (2008). Microenvironmental determinants of adult neural stem cell proliferation and lineage commitment in the healthy and injured central nervous system. Current Stem Cell Research \& Therapy, 3(3), 163-184.

35. Tropepe, V., Sibilia, M., Ciruna, B. G., Rossant, J., Wagner, E. F., \& van der Kooy, D. (1999). Distinct neural stem cells proliferate in response to EGF and FGF in the developing mouse telencephalon. Developmental Biology, 208(1), 166-188.

36. Zhu, G., Mehler, M. F., Mabie, P. C., \& Kessler, J. A. (1999). Developmental changes in progenitor cell responsiveness to cytokines. Journal of Neuroscience Research, 56(2), 131-145.

37. Lillien, L., \& Raphael, H. (2000). BMP and FGF regulate the development of EGF-responsive neural progenitor cells. Development, 127(22), 4993-5005.

38. Gritti, A., Frölichsthal-Schoeller, P., Galli, R., et al. (1999). Epidermal and fibroblast growth factors behave as mitogenic regulators for a single multipotent stem cell-like population from the subventricular region of the adult mouse forebrain. Journal of Neuroscience, 19(9), 3287-3297.

39. Taupin, P., Ray, J., Fischer, W. H., et al. (2000). FGF-2responsive neural stem cell proliferation requires $\mathrm{CCg}$, a novel autocrine/paracrine cofactor. Neuron, 28(2), 385-397.

40. Freund, C., Ward-van Oostwaard, D., Monshouwer-Kloots, J., et al. (2008). Insulin redirects differentiation from cardiogenic mesoderm and endoderm to neuroectoderm in differentiating human embryonic stem cells. Stem Cells, 26(3), 724-733.

41. Desai, M., Li, T., \& Ross, M. G. (2011). Fetal hypothalamic neuroprogenitor cell culture: preferential differentiation paths induced by leptin and insulin. Endocrinology, 152(8), 3192-3201.

42. Baker, J., Liu, J. P., Robertson, E. J., \& Efstratiadis, A. (1993). Role of insulin-like growth factors in embryonic and postnatal growth. Cell, 75(1), 73-82.

43. Beck, K. D., Powell-Braxton, L., Widmer, H. R., Valverde, J., \& Hefti, F. (1995). Igfl gene disruption results in reduced brain size, CNS hypomyelination, and loss of hippocampal granule and striatal parvalbumin-containing neurons. Neuron, 14(4), 717-730.

44. Lehtinen, M. K., Zappaterra, M. W., Chen, X., et al. (2011). The cerebrospinal fluid provides a proliferative niche for neural progenitor cells. Neuron, 69(5), 893-905.

45. Arsenijevic, Y., Weiss, S., Schneider, B., \& Aebischer, P. (2001). Insulin-like growth factor-I is necessary for neural stem cell proliferation and demonstrates distinct actions of epidermal growth factor and fibroblast growth factor-2. Journal of Neuroscience, 21(18), 7194-7202.

46. Cooper, O., \& Isacson, O. (2004). Intrastriatal transforming growth factor alpha delivery to a model of Parkinson's disease induces proliferation and migration of endogenous adult neural progenitor cells without differentiation into dopaminergic neurons. Journal of Neuroscience, 24(41), 8924-8931.

47. Sharif, A., Legendre, P., Prévot, V., Allet, C., Romao, L., Studler, J. M., et al. (2007). Transforming growth factor alpha promotes sequential conversion of mature astrocytes into neural progenitors and stem cells. Oncogene, 26(19), 2695-2706.

48. Böttner, M., Krieglstein, K., \& Unsicker, K. (2000). The transforming growth factor-betas: structure, signaling, and roles in nervous system development and functions. Journal of Neurochemistry, 75(6), 2227-2240.

49. Kobayashi, T., Ahlenius, H., Thored, P., Kobayashi, R., Kokoaia, Z., \& Lindvall, O. (2006). Intracerebral infusion of glial cell line- derived neurotrophic factor promotes striatal neurogenesis after stroke in adult rats. Stroke, 37(9), 2361-2367.

50. Pahnke, J., Mix, E., Knoblich, R., et al. (2004). Overexpression of glial cell line-derived neurotrophic factor induces genes regulating migration and differentiation of neuronal progenitor cells. Experimental Cell Research, 297(2), 484-494.

51. Sabo, J. K., Kilpatrick, T. J., \& Cate, H. S. (2009). Effects of bone morphogenic proteins on neural precursor cells and regulation during central nervous system injury. Neurosignals, 17(4), 255-264.

52. Li, W., \& LoTurco, J. J. (2000). Noggin is a negative regulator of neuronal differentiation in developing neocortex. Developmental Neuroscience, 22(1-2), 68-73.

53. Lim, D. A., Tramontin, A. D., Trevejo, J. M., Herrera, D. G., García-Verdugo, J. M., \& Alvarez-Buylla, A. (2000). Noggin antagonizes BMP signaling to create a niche for adult neurogenesis. Neuron, 28(3), 713-726.

54. Huang, E. J., \& Reichardt, L. F. (2001). Neurotrophins: roles in neuronal development and function. Annual Review of Neuroscience, 24, 677-736.

55. Ghosh, A., \& Greenberg, M. E. (1995). Distinct roles for bFGF and NT-3 in the regulation of cortical neurogenesis. Neuron, 15 (1), 89-103.

56. Benraiss, A., Chmielnicki, E., Lerner, K., Roh, D., \& Goldman, S. A. (2001). Adenoviral brain-derived neurotrophic factor induces both neostriatal and olfactory neuronal recruitment from endogenous progenitor cells in the adult forebrain. Journal of Neuroscience, 21(17), 6718-6731.

57. Islam, O., Loo, T. X., \& Heese, K. (2009). Brain-derived neurotrophic factor (BDNF) has proliferative effects on neural stem cells through the truncated TRK-B receptor, MAP kinase, AKT, and STAT-3 signaling pathways. Current Neurovascular Research, 6(1), 42-53.

58. Liu, X., Wang, Q., Haydar, T. F., \& Bordey, A. (2005). Nonsynaptic GABA signaling in postnatal subventricular zone controls proliferation of GFAP-expressing progenitors. Nature Neuroscience, 8(9), 1179-1187.

59. Kerever, A., Schnack, J., Vellinga, D., et al. (2007). Novel extracellular matrix structures in the neural stem cell niche capture the neurogenic factor fibroblast growth factor 2 from the extracellular milieu. Stem Cells, 25(9), 2146-2157.

60. Mercier, F., Kitasako, J. T., \& Hatton, G. I. (2002). Anatomy of the brain neurogenic zones revisited: fractones and the fibroblast/ macrophage network. The Journal of Comparative Neurology, 451(2), 170-188.

61. Lathia, J. D., Patton, B., Eckley, D. M., et al. (2007). Patterns of laminins and integrins in the embryonic ventricular zone of the CNS. The Journal of Comparative Neurology, 505(6), 630-643.

62. Georges-Labouesse, E., Mark, M., Messaddeq, N., \& Gansmüller, A. (1998). Essential role of alpha 6 integrins in cortical and retinal lamination. Current Biology, 8(17), 983-986.

63. Park, Y., Rangel, C., Reynolds, M. M., et al. (2003). Drosophila perlecan modulates FGF and hedgehog signals to activate neural stem cell division. Developmental Biology, 253(2), 247-257.

64. Kazanis, I., Lathia, J. D., Vadakkan, T. J., et al. (2010). Quiescence and activation of stem and precursor cell populations in the subependymal zone of the mammalian brain are associated with distinct cellular and extracellular matrix signals. Journal of Neuroscience, 30(29), 9771-9781.

65. Wang, L., Zhang, Z. G., Zhang, R. L., et al. (2006). Matrix metalloproteinase 2 (MMP2) and MMP9 secreted by erythropoietinactivated endothelial cells promote neural progenitor cell migration. Journal of Neuroscience, 26(22), 5996-6003.

66. Tzu, J., \& Marinkovich, M. P. (2008). Bridging structure with function: structural, regulatory, and developmental role of laminins. The International Journal of Biochemistry \& Cell Biology, 40(2), 199-214. 
67. De Arcangelis, A., Mark, M., Kreidberg, J., Sorokin, L., \& Georges-Labouesse, E. (1999). Synergistic activities of alpha3 and alpha6 integrins are required during apical ectodermal ridge formation and organogenesis in the mouse. Development, 126 (17), 3957-3968.

68. Loulier, K., Lathia, J. D., Marthiens, V., et al. (2009). beta1 integrin maintains integrity of the embryonic neocortical stem cell niche. PLoS Biology, 7(8), e1000176.

69. Hunter, D. D., Llinas, R., Ard, M., Merlie, J. P., \& Sanes, J. R. (1992). Expression of s-laminin and laminin in the developing rat central nervous system. The Journal of Comparative Neurology, 323(2), 238-251.

70. Johansson, S., Svineng, G., Wennerberg, K., Armulik, A., \& Lohikangas, L. (1997). Fibronectin-integrin interaction. Frontiers in Bioscience, 2, d126-d146.

71. Thorsteinsdóttir, S. (1992). Basement membrane and fibronectin matrix are distinct entities in the developing mouse blastocyst. Anatomical Record, 232(1), 141-149.

72. George, E. L., Georges-Labouesse, E. N., Patel-King, R. S., Rayburn, H., \& Hynes, R. O. (1993). Defects in mesoderm, neural tube and vascular development in mouse embryos lacking fibronectin. Development, 119(4), 1079-1091.

73. Sheppard, A. M., Brunstrom, J. E., Thornton, T. N., et al. (1995). Neuronal production of fibronectin in the cerebral cortex during migration and layer formation is unique to specific cortical domains. Developmental Biology, 172(2), 504-518.

74. Fox, M. A., Sanes, J. R., Borza, D.-B., et al. (2007). Distinct target-derived signals organize formation, maturation, and maintenance of motor nerve terminals. Cell, 129(1), 179-193.

75. Martínez-Morales, J. R., Barbas, J. A., Martí, E., Bovolenta, P., Edgar, D., \& Rodríguez-Tébar, A. (1997). Vitronectin is expressed in the ventral region of the neural tube and promotes the differentiation of motor neurons. Development, 124(24), 5139-5147.

76. Hynes, R. O. (1992). Integrins: versatility, modulation, and signaling in cell adhesion. Cell, 69(1), 11-25.

77. Pons, S., \& Martí, E. (2000). Sonic hedgehog synergizes with the extracellular matrix protein vitronectin to induce spinal motor neuron differentiation. Development, 127(2), 333-342.

78. Murase, S., \& Hayashi, Y. (1998). Concomitant expression of genes encoding integrin alpha $\mathrm{v}$ beta 5 heterodimer and vitronectin in growing parallel fibers of postnatal rat cerebellum: a possible role as mediators of parallel fiber elongation. The Journal of Comparative Neurology, 397(2), 199-212.

79. Chiquet-Ehrismann, R. (2004). Tenascins. The International Journal of Biochemistry \& Cell Biology, 36(6), 986-990.

80. Liao, H., Huang, W., Schachner, M., et al. (2008). Beta 1 integrinmediated effects of tenascin-R domains EGFL and FN6-8 on neural stem/progenitor cell proliferation and differentiation in vitro. Journal of Biological Chemistry, 283(41), 27927-27936.

81. Bronner-Fraser, M. (1988). Distribution and function of tenascin during cranial neural crest development in the chick. Journal of Neuroscience Research, 21(2-4), 135-147.

82. Garcion, E., Halilagic, A., Faissner, A., \& ffrench-Constant, C. (2004). Generation of an environmental niche for neural stem cell development by the extracellular matrix molecule tenascin C. Development, 131(14), 3423-3432.

83. Martin, P. T., \& Sanes, J. R. (1997). Integrins mediate adhesion to agrin and modulate agrin signaling. Development, 124(19), 3909-3917.

84. Storms, S. D., Kim, A. C., Tran, B. H., Cole, G. J., \& Murray, B. A. (1996). NCAM-mediated adhesion of transfected cells to agrin. Cell Adhesion and Communication, 3(6), 497-509.

85. Sugiyama, J., Bowen, D. C., \& Hall, Z. W. (1994). Dystroglycan binds nerve and muscle agrin. Neuron, 13(1), 103-115.

86. Meier, T., Masciulli, F., Moore, C., et al. (1998). Agrin can mediate acetylcholine receptor gene expression in muscle by aggregation of muscle-derived neuregulins. The Journal of Cell Biology, 141(3), 715-726.

87. Carlin, B., Jaffe, R., Bender, B., \& Chung, A. E. (1981). Entactin, a novel basal lamina-associated sulfated glycoprotein. Journal of Biological Chemistry, 256(10), 5209-5214.

88. Kohfeldt, E., Sasaki, T., Göhring, W., \& Timpl, R. (1998). Nidogen2: a new basement membrane protein with diverse binding properties. Journal of Molecular Biology, 282(1), 99-109.

89. Alonso, M. I., Moro, J. A., Martín, C., et al. (2009). Chondroitin sulphate-mediated fusion of brain neural folds in rat embryos. Cells Tissues Organs (Print), 189(6), 391-402.

90. Duband, J. L., Rocher, S., Chen, W. T., Yamada, K. M., \& Thiery, J. P. (1986). Cell adhesion and migration in the early vertebrate embryo: location and possible role of the putative fibronectin receptor complex. The Journal of Cell Biology, 102(1), 160-178.

91. Krotoski, D. M., Domingo, C., \& Bronner-Fraser, M. (1986). Distribution of a putative cell surface receptor for fibronectin and laminin in the avian embryo. The Journal of Cell Biology, 103(3), 1061-1071.

92. Pruszak, J., Ludwig, W., Blak, A., Alavian, K., \& Isacson, O. (2009). $\mathrm{CD} 15, \mathrm{CD} 24$, and CD29 define a surface biomarker code for neural lineage differentiation of stem cells. Stem Cells, 27(12), 2928-2940.

93. Hall, P. E., Lathia, J. D., Miller, N. G. A., Caldwell, M. A., \& ffrench-Constant, C. (2006). Integrins are markers of human neural stem cells. Stem Cells, 24(9), 2078-2084.

94. Montanaro, F., \& Carbonetto, S. (2003). Targeting dystroglycan in the brain. Neuron, 37(2), 193-196.

95. Hienola, A., Tumova, S., Kulesskiy, E., \& Rauvala, H. (2006). $\mathrm{N}$-syndecan deficiency impairs neural migration in the brain. The Journal of Cell Biology, 174(4), 569-580.

96. Anton, E. S., Kreidberg, J. A., \& Rakic, P. (1999). Distinct functions of alpha3 and alpha(v) integrin receptors in neuronal migration and laminar organization of the cerebral cortex. Neuron, 22(2), 277-289.

97. Jacques, T. S., Relvas, J. B., Nishimura, S., et al. (1998). Neural precursor cell chain migration and division are regulated through different beta1 integrins. Development, 125(16), 3167-3177.

98. Schmid, R. S., \& Anton, E. S. (2003). Role of integrins in the development of the cerebral cortex. Cerebral Cortex, 13(3), 219-224.

99. Sakaguchi, M., Imaizumi, Y., Shingo, T., et al. (2010). Regulation of adult neural progenitor cells by Galectin-1/beta1 Integrin interaction. Journal of Neurochemistry, 113(6), 1516-1524.

100. Suzuki, Y., Yanagisawa, M., Yagi, H., Nakatani, Y., \& Yu, R. K. (2010). Involvement of betal-integrin up-regulation in basic fibroblast growth factor- and epidermal growth factor-induced proliferation of mouse neuroepithelial cells. Journal of Biological Chemistry, 285(24), 18443-18451.

101. Leone, D. P., Relvas, J. B., Campos, L. S., et al. (2005). Regulation of neural progenitor proliferation and survival by beta1 integrins. Journal of Cell Science, 118(Pt 12), 2589-2599.

102. McCarty, J. H., Lacy-Hulbert, A., Charest, A., et al. (2005). Selective ablation of alphav integrins in the central nervous system leads to cerebral hemorrhage, seizures, axonal degeneration and premature death. Development, 132(1), 165-176.

103. Depaepe, V., Suarez-Gonzalez, N., Dufour, A., et al. (2005). Ephrin signalling controls brain size by regulating apoptosis of neural progenitors. Nature, 435(7046), 1244-1250.

104. Qiu, R., Wang, X., Davy, A., et al. (2008). Regulation of neural progenitor cell state by ephrin-B. The Journal of Cell Biology, 181 (6), 973-983.

105. Calaora, V., Chazal, G., Nielsen, P. J., Rougon, G., \& Moreau, H. (1996). mCD24 expression in the developing mouse brain and in zones of secondary neurogenesis in the adult. Neuroscience, 73(2), 581-594.

106. Lien, W.-H., Klezovitch, O., \& Vasioukhin, V. (2006). Cadherincatenin proteins in vertebrate development. Current Opinion in Cell Biology, 18(5), 499-506. 
107. Tole, S., Kaprielian, Z., Ou, S. K., \& Patterson, P. H. (1995). FORSE-1: a positionally regulated epitope in the developing rat central nervous system. Journal of Neuroscience, 15(2), 957969.

108. Capela, A., \& Temple, S. (2002). LeX/ssea-1 is expressed by adult mouse CNS stem cells, identifying them as nonependymal. Neuron, 35(5), 865-875.

109. Capela, A., \& Temple, S. (2006). LeX is expressed by principle progenitor cells in the embryonic nervous system, is secreted into their environment and binds Wnt-1. Developmental Biology, 291 (2), 300-313.

110. Gadhoum, S. Z., \& Sackstein, R. (2008). CD15 expression in human myeloid cell differentiation is regulated by sialidase activity. Nature Chemical Biology, 4(12), 751-757.

111. Karpowicz, P., Willaime-Morawek, S., Balenci, L., DeVeale, B., Inoue, T., \& van der Kooy, D. (2009). E-Cadherin regulates neural stem cell self-renewal. Journal of Neuroscience, 29(12), 3885-3896.

112. Kadowaki, M., Nakamura, S., Machon, O., Krauss, S., Radice, G. L., \& Takeichi, M. (2007). N-cadherin mediates cortical organization in the mouse brain. Developmental Biology, 304(1), 22-33.

113. Rousso, D. L., Pearson, C. A., Gaber, Z. B., Miquelajaurequi, A., Li, S., Portera-Cailliau, C., Morrissey, E. E., \& Novitch, B. G. (2012). Foxp-mediated suppression of $\mathrm{N}$-cadherin regulates neuroepithelial character and progenitor maintenance in the CNS. Neuron, 74(2), 314-330.

114. Chalasani, K., \& Brewster, R. M. (2011). N-cadherin-mediated cell adhesion restricts cell proliferation in the dorsal neural tube. Molecular Biology of the Cell, 22(9), 1505-1515.

115. Van Hateren, N. J., Das, R. M., Hautbergue, G. M., Borycki, A.G., Placzek, M., \& Wilson, S. A. (2011). FatJ acts via the Hippo mediator Yap1 to restrict the size of neural progenitor cell pools. Development, 138(10), 1893-1902.

116. Valiente, M., Ciceri, G., Rico, B., \& Marín, O. (2011). Focal adhesion kinase modulates radial glia-dependent neuronal migration through connexin-26. Journal of Neuroscience, 31(32), 11678-11691.

117. Bittman, K. S. (1999). Differential regulation of connexin 26 and 43 in murine neocortical precursors. Cerebral Cortex, 9, 188-195.

118. Kawasaki, H., Mizuseki, K., Nishikawa, S., et al. (2000). Induction of midbrain dopaminergic neurons from ES cells by stromal cell-derived inducing activity. Neuron, 28(1), 31-40.

119. Perrier, A. L., Tabar, V., Barberi, T., et al. (2004). Derivation of midbrain dopamine neurons from human embryonic stem cells. Proceedings of the National Academy of Sciences of the United States of America, 101(34), 12543-12548.

120. Siegenthaler, J. A., Ashique, A. M., Zarbalis, K., et al. (2009). Retinoic acid from the meninges regulates cortical neuron generation. Cell, 139(3), 597-609.

121. Conover, J. C., Doetsch, F., Garcia-Verdugo, J. M., Gale, N. W., Yancopoulos, G. D., \& Alvarez-Buylla, A. (2000). Disruption of Eph/ephrin signaling affects migration and proliferation in the adult subventricular zone. Nature Neuroscience, 3(11), 10911097.

122. Ramírez-Castillejo, C., Sánchez-Sánchez, F., Andreu-Agulló, C., et al. (2006). Pigment epithelium-derived factor is a niche signal for neural stem cell renewal. Nature Neuroscience, 9(3), 331-339.

123. Tavazoie, M., Van der Veken, L., Silva-Vargas, V., et al. (2008). A specialized vascular niche for adult neural stem cells. Cell Stem Cell, 3(3), 279-288.

124. Javaherian, A., \& Kriegstein, A. (2009). A stem cell niche for intermediate progenitor cells of the embryonic cortex. Cerebral Cortex, 19 (Suppl 1), i70-i77.

125. Lois, C., García-Verdugo, J. M., \& Alvarez-Buylla, A. (1996). Chain migration of neuronal precursors. Science, 271(5251), 978-981.
126. Klezovitch, O., Fernandez, T. E., Tapscott, S. J., \& Vasioukhin, V. (2004). Loss of cell polarity causes severe brain dysplasia in Lgl1 knockout mice. Genes \& Development, 18(5), 559-571.

127. Weigmann, A., Corbeil, D., Hellwig, A., \& Huttner, W. B. (1997). Prominin, a novel microvilli-specific polytopic membrane protein of the apical surface of epithelial cells, is targeted to plasmalemmal protrusions of non-epithelial cells. Proceedings of the National Academy of Sciences of the United States of America, 94(23), 12425-12430.

128. Kosodo, Y., Suetsugu, T., Suda, M., et al. (2011). Regulation of interkinetic nuclear migration by cell cycle-coupled active and passive mechanisms in the developing brain. EMBO Journal, 30 (9), 1690-1704

129. Haydar, T. F., Ang, E., Jr., \& Rakic, P. (2003). Mitotic spindle rotation and mode of cell division in the developing telencephalon. Proceedings of the National Academy of Sciences of the United States of America, 100(5), 2890-2895.

130. Tsuda, S., Kitagawa, T., Takashima, S., et al. (2010). FAKmediated extracellular signals are essential for interkinetic nuclear migration and planar divisions in the neuroepithelium. Journal of Cell Science, 123(Pt 3), 484-496.

131. Reverte, C. G., Benware, A., Jones, C. W., \& LaFlamme, S. E. (2006). Perturbing integrin function inhibits microtubule growth from centrosomes, spindle assembly, and cytokinesis. The Journal of Cell Biology, 174(4), 491-497.

132. Toyoshima, F., \& Nishida, E. (2007). Spindle orientation in animal cell mitosis: roles of integrin in the control of spindle axis. Journal of Cellular Physiology, 213(2), 407-411.

133. Engler, A. J., Sen, S., Sweeney, H. L., \& Discher, D. E. (2006). Matrix elasticity directs stem cell lineage specification. Cell, 126 (4), 677-689

134. Saha, K., Keung, A. J., Irwin, E. F., Li, Y., Little, L., Schaffer, D. V., \& Healy, K. E. (2008). Substrate modulus directs neural stem cell behavior. Biophysical Journal, 95(9), 4426-4438.

135. Halder, G., \& Johnson, R. L. (2011). Hippo signaling: growth control and beyond. Development, 138(1), 9-22.

136. Cao, X., Pfaff, S. L., \& Gage, F. H. (2008). YAP regulates neural progenitor cell number via the TEA domain transcription factor Genes \& Development, 22(23), 3320-3334.

137. Schlegelmilch, K., Mohseni, M., Kirak, O., et al. (2011). Yap1 acts downstream of $\alpha$-catenin to control epidermal proliferation. Cell, 144(5), 782-795.

138. Van Essen, D. C. (1997). A tension-based theory of morphogenesis and compact wiring in the central nervous system. Nature, 385(6614), 313-318.

139. Hayashi, T., \& Carthew, R. W. (2004). Surface mechanics mediate pattern formation in the developing retina. Nature, 431(7009), 647-652.

140. Sakai, T., Li, S., Docheva, D., et al. (2003). Integrin-linked kinase (ILK) is required for polarizing the epiblast, cell adhesion, and controlling actin accumulation. Genes \& Development, 17(7), 926-940.

141. Hoffman, B. D., Grashoff, C., \& Schwartz, M. A. (2011). Dynamic molecular processes mediate cellular mechanotransduction. Nature, 475(7356), 316-323.

142. Saffary, R., \& Xie, Z. (2011). FMRP regulates the transition from radial glial cells to intermediate progenitor cells during neocortical development. Journal of Neuroscience, 31(4), 1427-1439.

143. Yu, B., Ma, H., Du, Z., et al. (2011). Involvement of calmodulin and actin in directed differentiation of rat cortical neural stem cells into neurons. International Journal of Molecular Medicine, 28(5), 739-744.

144. Learish, R. D., Bruss, M. D., \& Haak-Frendscho, M. (2000). Inhibition of mitogen-activated protein kinase kinase blocks proliferation of neural progenitor cells. Brain Research. Developmental Brain Research, 122(1), 97-109. 
145. Graus-Porta, D., Blaess, S., Senften, M., et al. (2001). Beta1-class integrins regulate the development of laminae and folia in the cerebral and cerebellar cortex. Neuron, 31(3), 367-379.

146. Wang, B., Gao, Y., Xiao, Z., et al. (2009). Erk1/2 promotes proliferation and inhibits neuronal differentiation of neural stem cells. Neuroscience Letters, 461(3), 252-257.

147. Stavridis, M. P., Lunn, J. S., Collins, B. J., \& Storey, K. G. (2007). A discrete period of FGF-induced Erk1/2 signalling is required for vertebrate neural specification. Development, 134 (16), 2889-2894.

148. Hitoshi, S., Alexson, T., Tropepe, V., et al. (2002). Notch pathway molecules are essential for the maintenance, but not the generation, of mammalian neural stem cells. Genes \& Development, 16(7), 846-858.

149. Nakamura, Y., Sakakibara, S., Miyata, T., Ogawa, M., Shimazaki, T., Weiss, S., Kageyama, R., \& Okano, H. (2000). The bHLH gene hes1 as a repressor of the neuronal commitment of CNS stem cells. Journal of Neuroscience, 20(1), 283-293.

150. Campos, L. S., Decker, L., Taylor, V., \& Skarnes, W. (2006). Notch, epidermal growth factor receptor, and beta1-integrin pathways are coordinated in neural stem cells. Journal of Biological Chemistry, 281(8), 5300-5309.

151. Legate, K. R., Wickström, S. A., \& Fässler, R. (2009). Genetic and cell biological analysis of integrin outside-in signaling. Genes \& Development, 23(4), 397-418.

152. Spiering, D., \& Hodgson, L. (2011). Dynamics of the Rho-family small GTPases in actin regulation and motility. Cell Adhesion \& Migration, 5(2), 170-180.

153. Chen, L., Melendez, J., Campbell, K., Kuan, C.-Y., \& Zheng, Y. (2009). Rac1 deficiency in the forebrain results in neural progenitor reduction and microcephaly. Developmental Biology, 325(1), $162-170$.

154. Cappello, S., Attardo, A., Wu, X., et al. (2006). The Rho-GTPase cdc42 regulates neural progenitor fate at the apical surface. Nature Neuroscience, 9(9), 1099-1107.

155. Magri, L., Cambiaghi, M., Cominelli, M., et al. (2011). Sustained activation of mTOR pathway in embryonic neural stem cells leads to development of tuberous sclerosis complex-associated lesions. Cell Stem Cell, 9(5), 447-462.

156. Endo, M., Antonyak, M. A., \& Cerione, R. A. (2009). Cdc42mTOR signaling pathway controls Hes5 and Pax6 expression in retinoic acid-dependent neural differentiation. Journal of Biological Chemistry, 284(8), 5107-5118.

157. Guillemot, F. (1999). Vertebrate bHLH genes and the determination of neuronal fates. Experimental Cell Research, 253(2), 357-364.

158. Ohtsuka, T., Sakamoto, M., Guillemot, F., \& Kageyama, R. (2001). Roles of the basic helix-loop-helix genes Hes 1 and
Hes5 in expansion of neural stem cells of the developing brain. Journal of Biological Chemistry, 276(32), 30467-30474.

159. Osumi, N., Shinohara, H., Numayama-Tsuruta, K., \& Maekawa, M. (2008). Concise review: Pax6 transcription factor contributes to both embryonic and adult neurogenesis as a multifunctional regulator. Stem Cells, 26(7), 1663-1672.

160. Lyden, D., Young, A. Z., Zagzag, D., et al. (1999). Id1 and Id3 are required for neurogenesis, angiogenesis and vascularization of tumour xenografts. Nature, 401(6754), 670-677.

161. Bai, G., Sheng, N., Xie, Z., et al. (2007). Id sustains Hes 1 expression to inhibit precocious neurogenesis by releasing negative autoregulation of Hes1. Developmental Cell, 13(2), 283297.

162. Yun, K., Mantani, A., Garel, S., Rubenstein, J., \& Israel, M. A. (2004). Id4 regulates neural progenitor proliferation and differentiation in vivo. Development, 131(21), 5441-5448.

163. Niola, F., Zhao, X., Singh, D., Castano, A., Sullivan, R., Lauria, M., et al. (2012). Id proteins synchronize stemness and anchorage to the niche of neural stem cells. Nature Cell Biology, Apr 22 [Epub ahead of print]

164. Knoepfler, P. S., Cheng, P. F., \& Eisenmann, R. N. (2002). N-myc is essential during neurogenesis for the rapid expansion of progenitor cell populations and the inhibition of neuronal differentiation. Genes \& Development, 16(20), 2699-2712.

165. Nagao, M., Campbell, K., Burns, K., Kuan, C. Y., Trumpp, A., \& Nakafuku, M. (2008). Coordinated control of self-renewal and differentiation of neural stem cells by Myc and the p19ARF-p53 pathway. The Journal of Cell Biology, 183(7), 1243-1257.

166. Zebedee, Z., \& Hara, E. (2001). Id proteins in cell cycle control and cellular senescence. Oncogene, 20(58), 8317-8325.

167. Calegari, F., Haubensak, W., Haffner, C., \& Huttner, W. B. (2005). Selective lengthening of the cell cycle in the neurogenic subpopulation of neural progenitor cells during mouse brain development. Journal of Neuroscience, 25(28), 6533-6538.

168. Lukaszewicz, A., Savatier, P., Cortay, V., et al. (2005). G1 phase regulation, area-specific cell cycle control, and cytoarchitectonics in the primate cortex. Neuron, 47(3), 353-364.

169. Sun, Y., Goderie, S. K., \& Temple, S. (2005). Asymmetric distribution of EGFR receptor during mitosis generates diverse CNS progenitor cells. Neuron, 45(6), 873-886.

170. Lutolf, M. P., \& Hubbbell, J. A. (2005). Synthetic biomaterials as instructive extracellular microenvironments for morphogenesis in tissue engineering. Nature Biotechnology, 23(1), 47-55.

171. Eiraku, M., Takata, N., Ishibashi, H., Kawada, M., Sakakura, E., Okuda, S., Sekiguchi, K., Adachi, T., \& Sasai, Y. (2011). Selforganizing optic-cup morphogenesis in three-dimensional culture. Nature, 472(7341), 51-56. 